\title{
A Report on the Distribution of Selected Employment Benefits of Older Workers
}

\author{
LeaAnne DeRigne $^{1 *}$, PhD; Patricia A. Stoddard-Dare ${ }^{2}, \mathrm{PhD}$; \\ Cyleste C. Collins², PhD; Linda M. Quinn ${ }^{3}, \mathrm{PhD}$
}

${ }^{1}$ Phyllis and Harvey Sandler School of Social Work, Florida Atlantic University, 777 Glades Drive, Boca Raton, FL, 33431

\author{
${ }^{2}$ School of Social Work, Cleveland State University \\ ${ }^{3}$ Department of Mathematics, Cleveland State University \\ *Iderigne@fau.edu
}

Keywords: paid sick leave, flexible work, vacation time

\begin{abstract}
Vigorous legislative activity is taking place regarding paid sick leave. Most existing research measures paid sick days autonomously without also considering other benefits such as flexible work and paid vacation. This descriptive study of a nationally representative sample of 4428 adult male workers finds $77.1 \%$ of workers have a combination of paid sick leave, flexible work, and vacation, while only $16.8 \%$ have just one of the three benefits. Future research should examine the correlates of combined benefit packages in terms of workers' physical, emotional and financial health and wellbeing. Nationally representative data collection efforts should refine the measurement of workplace benefit variable to allow for these comparisons.
\end{abstract}

\section{Introduction}

Access to paid sick leave, vacation time, and flexible work can be an important support for American workers as they struggle to balance the responsibilities of their jobs, families, and health ${ }^{12} 3$. Campaigns for mandating paid sick leave across the country have been snowballing over the past few years with 10 states, Washington DC, and 33 municipalities passing legislation mandating between 3 and 9 days of paid sick leave ${ }^{4}$. At the same time, 15 states have passed legislation that preemptively blocks paid sick leave mandates ${ }^{5}$. Legislation at the federal level (the Healthy Families Act) has been proposed in the past several Congressional sessions. It would have mandated paid sick leave of up to 7 days at employers with more than 15 employees and 7 unpaid days if they work at smaller companies (S. 636 \& H.R. 1516, 2018). The bills stalled; however, and American workers still have no federal guarantee of any paid time off work (vacation or sick). The only federal law that allows for protected leave is the Family and Medical Leave Act (FMLA), which provides unpaid leave (up to 12 weeks) after the birth or adoption of a child or for one's own illness or a close family member's health care crisis.

There are also no federally mandated policies on vacation time in the United States Fair Labor Standards Act. Access to vacation time is considered a discretionary workplace fringe benefit and often increases with seniority at a workplace. Americans are also known for not taking their vacation days leaving millions of days unused across the country. Flexible work is also not a workplace right but rather a scenario that is often offered at the pleasure of individuals employers and even supervisors. In order to really understand how any of these benefits might impact employees, researchers need to begin to analyze all three benefits together (sick leave, vacation time and flexible work options).

\section{Previous Literature}

According to the Bureau of Labor Statistics (2017) roughly $60 \%$ of US civilian employees have access to paid sick leave and paid vacation time. Part time workers are even less likely to be covered as are workers in smaller companies. Research has found that not having paid sick and vacation leave 
are associated with a range of negative outcomes ${ }^{1,2,6-8}$. Workers without paid sick leave are less likely to time off of work when ill or when their family members are ill ${ }^{1}$. The public health implications of this reality could be staggering resulting in the spread of contagious illness such as the flu virus. Research has also found that workers with sick leave are more likely to have obtained preventive health care screenings ${ }^{2}$. Finally, workers without paid sick leave report higher levels of psychological distress $^{6}$. It is clear paid sick leave is related to health care outcomes in workers. What is not known is how vacation time and flexible work may stand in as proxies for access to paid sick leave.

Justification for the Study. Policymakers and human resource professionals need empirical data to inform their practice and policy decisions. Currently, researchers are at a loss when trying to demonstrate the prevalence and distribution of various benefit packages. This lack of basic knowledge impedes the empirical investigation of the correlates of these benefits packages. Important questions that need to be asked include, how do paid sick leave, flex time, and paid vacation interact, and what are the outcomes of various benefit packages in terms of worker physical, emotional and financial health and wellbeing? The first step is identifying nationally representative samples of workers on which to explore the current distribution of benefits.

Given the significant legislative activity around the issue, it is necessary to gather more information about the advantages and disadvantages of workplace benefit combinations. Currently, policymakers and human resource professionals have only a small evidence base on which to make decisions about the best benefits packages that enable a strong work ethic, being family-friendly, and promoting a healthy and stable work-life balance for their workers. An empirical study of the correlates of various benefit packages is needed and can assist in such decisions. While there are some existing research reports on paid sick leave prevalence and vacation leave, no studies, to our knowledge, have examined the benefits together. The U.S. Bureau of Labor Statistics, for example, reports on paid sick leave and paid vacation but does not include information on flexible work or paid time off (PTO) ${ }^{9}$.

\section{Methods}

The 2012 cross-section of the nationally representative National Longitudinal Survey of Youth1979 (NLSY79) was used for this analysis. The NLYS79 data were collected using computer-assisted personal interviews. The analytic sample included $\mathrm{N}=4428$ adult workers ages $47-55$ in 2012 . The NLSY is sponsored by the U.S. Department of Labor, Bureau of Labor Statistics. A random sample of housing units was taken in 1978 in selected areas of the country to identify individuals ages 14-21 as of December, 31, 1978. Then a random sample was taken again to select those individuals to be interviewed. A set of supplemental samples was drawn to oversample Hispanic and black youth as well as economically disadvantaged youth. There was also a sample of military households taken in order to be able to compare civilian and non-civilian households. Two organizations contract with the DOL to conduct the study, The Center for Human Resource Research at The Ohio State University and NORC at the University of Chicago. Interviews were conducted yearly until 1994 and are now conducted only in even-numbered years. The U.S. Office of Management and Budget (OMB) has approved the questionnaire, protects confidentiality and manages the data. Researchers accessing data are only given non-identifying data and analysis is considered secondary data analysis thus. For more detailed information on the survey see https://www.nlsinfo.org/content/cohorts/nlsy79/intro-tothe-sample).

Measured variables include "How many paid sick days with full pay [are/were] you entitled to each year?"; "How many days of paid vacation [are/were] you entitled to each year?"; "Did your employer make available to you flexible hours or work schedule?" To measure "paid time off" (PTO) respondents were asked the "Number of paid sick/vacation days combined [are/were] you entitled to each year." Excluded from the analysis were those who had missing values on any of the variables on interest. Descriptive statistics were generated for each employment benefit individually, and for each combination of employment benefits packages for paid sick leave, flexible work, and vacation. 


\section{Results}

Descriptive statistics were run to explore the most common benefit packages and common combinations of benefits. Flexible work, paid sick leave and vacation were examined together. Persons with paid time off (PTO), which includes paid sick and vacation time were included in the counts of paid sick and vacation leave. The final sample size was 4,428 (see Table 1 ). Only $6 \%$ of the sample reported having none of the benefits, $16.8 \%$ have only a single benefit, while $77.1 \%$ have a combined package.

Table 1 Frequency distribution for combinations of three workplace benefits ( $\mathrm{n}=4428$ working US adults) in 2012

\begin{tabular}{|c|c|c|c|c|}
\hline $\begin{array}{c}\text { Has Flexible Work } \\
\text { Benefit }\end{array}$ & $\begin{array}{c}\text { Has Paid Sick Leave } \\
\text { Days }\end{array}$ & $\begin{array}{c}\text { Has Paid Vacation } \\
\text { Days }\end{array}$ & Frequency & Percent \\
\hline No & No & No & 268 & 6.1 \\
\hline No & No & Yes & 314 & 7.1 \\
\hline No & Yes & No & 134 & 3.0 \\
\hline No & Yes & Yes & 1140 & 25.8 \\
\hline Yes & No & No & 298 & 6.7 \\
\hline Yes & No & Yes & 303 & 6.8 \\
\hline Yes & Yes & No & 67 & 1.5 \\
\hline Yes & Yes & Yes & 1904 & 43.0 \\
\hline No & & & 1856 & 41.9 \\
\hline \multirow[t]{5}{*}{ Yes } & & & 2572 & 58.1 \\
\hline & No & & 1183 & 26.7 \\
\hline & Yes & & 3245 & 73.3 \\
\hline & & No & 767 & 17.3 \\
\hline & & Yes & 3661 & 82.7 \\
\hline
\end{tabular}

Most Common, Least Common Benefits. The category with the smallest number of workers was flexible work and paid sick leave, with only a small proportion (less than $2 \%$ ) reporting having just these two benefits. The second least frequently reported benefit package was having paid sick leave only, with only $3 \%$ having only that benefit.

The most frequently occurring benefit package representing more than $40 \%$ of workers, was a package that includes flexible work, paid sick leave, and vacation time together, while the next most frequently reported combination was having paid sick leave and vacation leave only, representing a little more than one-quarter of workers. After these two categories, there is a large drop in the proportion reporting--vacation only was the next most frequently reported benefit with just over 7\% reporting having it. Below, the findings are explained within each benefit category.

Vacation Leave. Among those with any vacation leave $(n=3,661), 8.6 \%$ had only vacation leave, about one-third (31.1\%) had paid sick leave and vacation leave, $8.3 \%$ had flex and vacation leave only, and more than half $(52 \%)$ had all three types of leave. 
Paid Sick Leave. Among those with any paid sick leave $(n=3,245), 4.1 \%$ had paid sick leave only, more than one-third $(35.1 \%)$ had paid sick leave and vacation leave, only $2.1 \%$ had a combination of paid sick leave and flex, and more than half $(58.7 \%)$ had all three types of leave.

Flexible Work. Among those with any flexible work schedule arrangement ( $\mathrm{n}=2,572)$, nearly three-quarters (74\%) had all three types of benefits, while only $11.6 \%$ had flex only, $11.8 \%$ had flex and vacation, and $2.6 \%$ had flex and paid sick leave.

\section{Implications for Policy and Practice}

- This report fills a gap by drawing attention to a nationally representative dataset of older adult workers that allows comparison of various benefit packages.

- Here we find $16.1 \%$ of the sample has only one employment benefit while $77 \%$ has a combined benefit package with at least two of the three benefits examined.

- Much of the existing relevant empirical literature reports on the correlates of individual employment benefits, not on the correlates of combined benefit packages. Future research is needed in this area.

- Human resource planners and public health practitioners and policy makers need to be able to understand the distribution of combined benefits and how they might influence workers' physical, emotional, and financial health.

- Established nationally representative data collection efforts should ask specific questions about the number of paid sick leave days, and the number of paid and unpaid vacation days, and should collect details about flextime and flexplace benefits.

- Particular attention needs to be paid to those with no leave or only one benefit as they are likely the employees who are having the most difficulty balancing the competing demands of work, family and health.

\section{Discussion and Conclusion}

Workplace benefits' relationships to workers' health, wellbeing and family lives make them an essential but neglected concern for public health. This is the first known report which details the combined prevalence of paid sick leave, flexible work, and paid vacation days in a nationally representative sample of adult workers. We find while over three-quarters of the workers examined have a combination of paid sick leave, flexible work, and paid vacation, only $16 \%$ of the workers studied have just one of these benefits. There is a mismatch between workers realities (various benefit package combinations) and the body of empirical research which often evaluates paid sick leave, flexible work, and paid vacation separately.

Given the impact workplace benefits have on workers' everyday lives, it is essential that more research is conducted to fully understand the extent to which type and combination of leave matters, both in the management of conflicting work and health caregiving responsibilities and in maximizing employee productivity. To date, researchers and policymakers have not been able to report on the combination of leave benefits when describing American workers' access to paid leave and flexible work options. More research is needed to determine to what extent workers actually take leave and for what purpose with the hope that policymakers and human resource planners are better able to put together leave packages that successfully support the American workforce.

Funding: No funding was received for this study.

Financial Disclosure: There are no financial disclosures for the authors of this study.

Conflicts of Interest: The authors have no potential conflicts of interest to disclose.

Acknowledgments: There are no acknowledgments for this study.

Human Participant Compliance Statement: Secondary data analysis was conducted and therefore a protocol approval was not needed.

Word Count: 1210 excluding abstract, tables, figures, references, Implications for Policy \& Practice 


\section{References}

[1] DeRigne L, Stoddard-Dare P, Quinn L. Workers Without Paid Sick Leave Less Likely To Take Time Off For Illness Or Injury Compared To Those With Paid Sick Leave. Health Aff (Millwood). 2016;35(3):520-527. doi:10.1377/hlthaff.2015.0965

[2] DeRigne L, Stoddard-Dare P, Collins C, Quinn L. Paid sick leave and preventive health care service use among U.S. working adults. Prev Med. 2017;99:58-62. doi:10.1016/j.ypmed.2017.01.020

[3] Stoddard-Dare P, DeRigne L, Quinn L, Mallett C. Paid sick leave status in relation to government sponsored welfare utilization. Am J Orthopsychiatry. 2018;88(5):608-615. doi:10.1037/ort0000318

[4] National Partnership for Women and Families: Current sick days laws. National Partnership for Women and Families. http://www.paidsickdays.org/research-resources/current-sick-dayslaws.html. Accessed February 20, 2019.

[5] Covert B, Popp E. The conservative backlash against minimum wage and paid sick leave victories sweeping the nation. ThinkProgress. June 2016. https://thinkprogress.org/theconservative-backlash-against-minimum-wage-and-paid-sick-leave-victories-sweeping-thenation-61f26429300a/. Accessed September 16, 2017.

[6] Stoddard-Dare P, DeRigne L, Collins CC, Quinn LM, Fuller K. Paid sick leave and psychological distress: An analysis of U.S. workers. Am J Orthopsychiatry. September 2017. doi:10.1037/ort0000293

[7] Strandberg T e., von Bonsdorff M, Strandberg A, Pitkälä K, Räikkönen K. Research paper: Associations of vacation time with lifestyle, long-term mortality and health-related quality of life in old age: The Helsinki Businessmen Study. Eur Geriatr Med. 2017;8:260-264. doi:10.1016/j.eurger.2017.03.003

[8] Gump B, Matthews K. Are vacations good for your health? The 9-year mortality experience after the multiple risk factor intervention trial. Psychosom Med. 2000;62(5):608-612.

[9] U.S. Bureau of Labor Statistics: Corrections to Estimates of Access to Paid Sick Leave Benefits. U.S. Bureau of Labor Statistics: Corrections to Estimates of Access to Paid Sick Leave Benefits. https://www.bls.gov/ncs/ebs/errata_07212017.xlsx. Published 2017. Accessed September 16, 2017. 